\title{
Mobile Learning for Early Detection Cancer
}

\author{
https://doi.org/10.3991/ijim.v12i2.7814 \\ Hery Harjono Muljo, Anzaludin Samsinga Perbangsa, Yulius, Bens Pardamean $\left.{ }^{\square}\right)$ \\ Bina Nusantara University, Jakarta, Indonesia \\ bpardamean@binus .edu
}

\begin{abstract}
Information and communication technology continues to grow and affects many areas of life, including the field of health, especially cancer. The development of health knowledge can be disseminated by utilizing mobile application based learning technology as media. Many things have been done by the government through special programs, among others, carried out breast cancer awareness campaign through breast self-screening program. The positive impact of this effort has led to mobile applications for learning about early detection of cancer in Indonesia. The development of mobile learning is a continuation of previous online learning to help the process of early detection of cervical cancer. Data collection methods used observation, interview, and questionnaire techniques, while instructional designs use the ADDIE (Analysis Design Development Implementation Evaluations) model and methods for developing object-oriented programming systems using Unified Modeling Language (UML). The resulting output is the application of early detection of cancer-based mobile learning which is the virtue of this study.
\end{abstract}

Keywords-cancer, early detection, mobile learning

\section{Introduction}

The rapid development of technology has had an impact on the world of education and led to mobile learning which is an important part of the education system [1]. While thinking about education must also take into account the type of technology that will be used to support that education [2].

Mobile learning is a learning model that utilizes information and communication technology [3] using handheld technology devices, such as Personal Digital Assistant (PDA), mobile telephone, laptop, and tablet PC in teaching and learning process [4]. In addition, there is a mention of mobile learning as a combination of mobile computing technologies and electronic education technology [5] which results in a learning experience regardless of time and place [6] while mobile computing is a means for delivering mobile learning materials which can be accessed without bound by space and time [7].

Mobile technology has the potential for innovation in education as it provides learning facilities in an important context, and also mobility and mobile technology capabilities can make learning affordable anywhere [8]. Users can use the mobile device while doing the task or continue the learning activities outside the classroom. 
Mobile devices with cameras and GPS provide a variety of uses in learning such as data collection, documentation on the field and field research [9].

Mobile app innovation can increase the interest of teachers, as it provides various facilities for teaching and learning [10]. Teachers can use developed visual programming languages such as App Inventor (AI) by Google and the Massachusetts Institute of Technology allowing everyone with a Google account to create prototypes and develop Android mobile apps through easier programming languages [11].

The development of Mobile Learning for Early Detection Cervical Cancer is a continuation of previous research of the online learning content and learning management system for the Early Detection of Cervical Cancer [12] as well as to address the challenges of Indonesia's vast geographic area, the limited number of resources human, and requires a high enough cost in implementing the program of early detection of cervical cancer.

One of the efforts of the Ministry of Health, the campaign of breast cancer awareness through breast self-examination program, and has been determined October as "Breast Cancer Awareness Month". The positive impact of this entity has led to a mobile application for online learning on early detection of breast cancer in Indonesia. Pink Band from Indosat and Love Pink Breasties made by Love Pink Indonesia Community is a mobile application for early detection of breast cancer based on IOS and Android. Both applications are intended for the general public in Indonesia so that the information provided has also been adjusted to be digested for all walks of life.

\subsection{Benefits of Mobile Learning}

The use of mobile devices as a learning medium can enhance collaboration and relationships among users through online mobile devices [13] and support remote learning programs, access learning content anywhere and anytime, and allow users to collaborate on learning activities [14] so that users can work with each other to complete their tasks [15].

Mobile learning applications can also help educate and eliminate constraints faced by users in learning by simplifying the learning process, as well as easing the level of pressure faced by learners and helping to meet the needs of learners [16]. Users strongly support the use of mobile learning applications because it has wireless technology that increases the flexibility in accessing learning resources [17].

The use of mobile devices enhances the user's convenience in learning activities [18] and can support individual learning as well as collaborative learning and can increase the user's confidence level [19].

\subsection{The Challenges of M-Learning}

One of the significant challenges of mobile learning is diversity. Some of the diversity that exists for handheld mobile devices features feature phones with tiny screens and numeric keypads, for smartphones featuring AZ keypads and mid-sized screens, and for touch phones featuring a device-sized screen activated by touch [20]. 
The second challenge is download speed and Internet access. Users are often faced with the problem of slow download speeds and limited Internet access and are aggravated by the high-speed broadband access. The third challenge is the limited capacity of RAM and it takes longer to retrieve data from external memory [21]. The fourth challenge is to enter text data. Users are sometimes awkward when entering information into a device using a numeric keypad [22].

\section{$2 \quad$ Method}

Sources of data were obtained from observation and analysis through observation by direct review of the training process of prevention of breast cancer and cervical cancer at the hospital, in-depth interviews of medical teams (doctors and midwives) and community related to treating breast and cervical cancer, and discussion with resource persons. In addition, literature studies were also conducted to obtain data or information about breast cancer and cervical cancer as well as information systems in designing system models. Then carried out system development strategy, the user needs identification, system design, content design, prototype development, implementation, and evaluation.

Another method to collect data was by means of questionnaires undertaken to identify user needs in designing the system using a pre-survey questionnaire.

The data obtained were grouped into several subsystems which were then be formed into a system design to form mobile-based learning applications. The steps taken in the research model of early cancer detection learning system using the ADDIE (Analysis, Design, Development, Implementation, Evaluation) model included [23]:

a) Analysis: In the analysis phase, the main consideration was the target user. Where needs analysis was done to determine the needs of users. Analyses were conducted by considering the standard aspects of learning and competence. In addition, this stage was needed to identify the current state, the need for mobile-based learning applications, and user readiness for mobile-based learning applications.

b) Design: At the design stage, the overall research and planning were carried out. In planning identified objectives and targets, determining how the goals and objectives were met, the learning strategies to be used, the media, and the methods that would be most effective for achieving the goals and objectives. During the design phase, consideration should be given to information or data from the analysis stage. Another thing to do was how the objectives would be assessed and determine the assessment to be performed before implementation. When aligning goals and objectives, it refered to the data analysis stage that provided the necessary information about user characteristics, information needs, and system requirements.

c) Development: The development stage referred to the results of the previous two stages and built the product of mobile-based learning applications as information media. Development stage emphasized 3 (three) factors, namely preparation, production, and evaluation. In this stage the development and selection of 
materials and media were performed, and a formative evaluation was conducted. The evaluation at this stage contained a different focus from the evaluation format than the other stages in the ADDIE process. A formative approach was done as drawing attention to the quality standards of mobile-based learning applications desired by users.

d) Implementation: In the implementation stage, the resulting product was intensified. In order for mobile-based learning application products to be effective, continuous analysis, redesign, and mobile-based learning applications were continuously analyzed.

e) Evaluation: The evaluation stage was an important component of the ADDIE and multidimensional processes. The evaluation stage occurred during the development stage in a formative evaluation, and in the implementation phase with the help of users (doctors, midwives, volunteers) in the form of evaluation of user responses to the design of mobile-based learning application system created. This was done for continuous improvement. It should be seen whether the problem has been resolved (relevant to the needs of the user), and objectives have been met. The evaluation phase was an integrated part in the continuation of effective analysis and implementation for future system improvements.

Activity design of mobile-based learning application system in principle was to develop the structure and algorithm of the system to meet the need for online learning dissemination of information prevention of breast cancer and cervical cancer. It depended on the support of the content, which had a high level of interactive, vivid simulation, video or audio, community-based, who has access to tutors and consists of a management-based site for the recording of progress for users and administrators.

The design of mobile application-based learning system program was done by using the Android programming language. The development of this system produced a prototype system that was tested by health volunteers and medical teams.

Currently, there are four operating systems most widely used in mobile devices, namely iOS, Android, Blackberry OS, and Windows Phone. Android is a Linux-based open-source operating system developed by Google to run on mobile devices, smartphones, and tablets [24].

Smartphones and tablets using Android operating systems can exchange data with database servers using JSON (JavaScript Object Notation) format and JSON parser features from Android. JSON is an independent data exchange format, not tied to a particular programming language. Because of its easy read-write and independent that makes JSON as the ideal format for exchange and data analysis. While JSON parser is one of the Android features to manage the interaction between Android application with the web server. The Android app and the database server can interact with the web server as shown in Figure 1 [25]. 


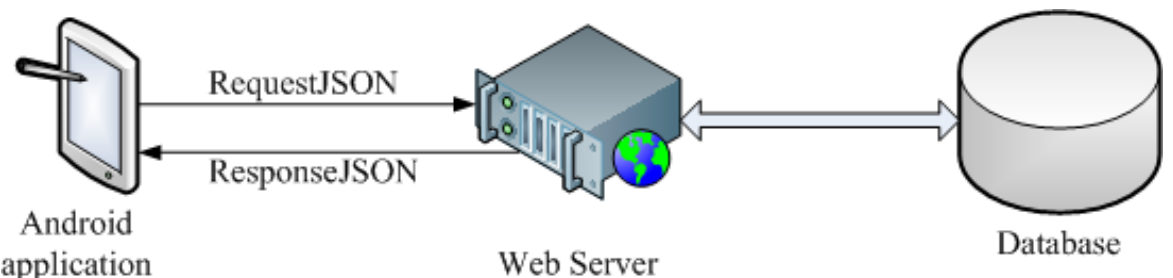

Fig. 1. Interaction of android apps with database [25]

The database used in mobile devices is SQLite, while in the server used MySQL database. SQLite and MySql are open source databases supported by multiple platforms. SQLite is widely applied in Android-based applications due to its flexibility and does not require large resources [26].

\section{$3 \quad$ Results}

\subsection{Mobile Learning Application Comparison}

The comparison of Moodle 1.8, Claroline 1.6, OLAT, and Sakai 2.3.1 in Table 1 shows that mobile learning application should have discussion forums, calendar, community, grading, authentication, and authorization features [27].

Table 1. Mobile Learning Application Comparison [27]

\begin{tabular}{|l|c|c|c|c|}
\hline \multirow{2}{*}{ Tools } & \multicolumn{4}{|c|}{ Mobile Learning Application } \\
\cline { 2 - 5 } & Moodle 1.8 & Claroline 1.6 & OLAT & Sakai 2.3.1 \\
\hline Discussion Forum & Y & Y & Y & Y \\
\hline File Exchange & Y & Y & Y & Y \\
\hline Real-time Chat & Y & Y & Y & Y \\
\hline Video Services & Y & N & N & N \\
\hline Calendar & Y & Y & Y & Y \\
\hline Community & Y & Y & Y & Y \\
\hline Student Portfolio & Y & Y & N & Y \\
\hline Authentication & Y & Y & Y & Y \\
\hline Authorization & Y & Y & Y & Y \\
\hline Online Grading & Y & Y & Y & Y \\
\hline Student Tracking & Y & Y & Y & Y \\
\hline
\end{tabular}

\subsection{User Requirement}

Based on the results of questionnaires and interviews with doctors at health centers, hospitals, and the Indonesian Cancer Foundation, it can be concluded that the goals to be achieved from the training of health volunteer and medical personnel for cancer early detection program are: 
1. increasing knowledge of trainees (knowledge);

2. increased expertise in practicing skill competency methods;

3. the establishment of ongoing communication (site preparation services);

4. behavioral changes to be more concerned about cancer and apply cancer early detection programs in daily practice (awareness);

Early cancer detection training can be followed by many communities, both medical and nonmedical, such as nurses, general practitioners, and other stakeholders with no special requirements. The number of training conducted for hospitals an average of 2-4 times a year. While Indonesia Cancer Foundation has been conducted 13 trainings in a year. The activities to be prepared before giving counseling consisted of creating teaching materials, props, facilities, delivery methods, reproductive health knowledge, interactive CDs, and leaflets. While the media used during the counseling, including artificial bodies (props), computers, slides (slide), audiovisuals, photos, $\mathrm{C} 2 /$ film, and real inspection tools such as Colposcopy cryotherapy.

The methods used during the counseling were lectures, discussions, group discussions, demos, and seminars (workshops). The average time required for each implementation of the cancer early detection training activities is about 2-3 days and is adjusted for a large number of participants. In the implementation of counseling, it was necessary to simulate or model in modeling the procedure of cancer early detection method. At the beginning of the training session a pre-test was performed and at the end of the training, a post-test was conducted to determine the level of understanding of the trainees.

Based on the results of the questionnaire from 100 participants in medical centers, it was found that majority of users chose to use smartphones to access learning materials $(88 \%)$, followed by tablets $(38 \%)$, and notebooks $(18 \%)$. The operating system on smartphones that users use is Android (64\%), iOS (37\%), and Windows Phone (12\%). The most needed features in mobile learning applications were learning materials $(71 \%)$, quiz $(37 \%)$, assistance $(35 \%)$, and forum discussion $(33 \%)$. The delivery medium that users expect in the video was $57 \%$, images $51 \%$, text $48 \%$, and voice $27 \%$.

\subsection{System Requirement}

The mobile learning application of early cancer detection was designed to help users (health volunteer and medical personnel) in learning content. This application was equipped with tools and facilities that can provide convenience for users in accessing data and information about cancer prevention. System requirements were based on FACTOR criteria: Functionality, Application Domain, Condition, Technology, Object, Responsibility.

a) Functionality: Mobile learning application of early detection of cancer made for dissemination (dissemination) information of cancer prevention. This application provides cancer prevention information that can be accessed easily, real time, and up to date. The resulting information can be the basis for the user in doing his job. 
b) Application Domain: The parties who use mobile learning early detection of this cancer, including administrators, participants (nurses and general practitioners), and expert doctors. This application allows users to interact with each other through the Forum to support the learning process.

c) Condition: This mobile learning application is used by health volunteers, midwives, nurses, and general practitioners who enthusiastically seek cancer prevention information and are accustomed in using an android smartphone.

d) Technology: This mobile based application can be used anytime anywhere and can be used on all Android smartphones that have an Internet connection. The system can be used on Android operating system platform with an Internet connection.

e) Object: The objects in this system are participants, courses, materials, tasks, and threads.

f) Responsibility: Overall application responsibility is a reliable administrative tool in providing information that supports the dissemination of cancer prevention information.

\subsection{Mobile Learning Application Design}

This mobile learning cancer application has required features, such as Forum, Chat, Quiz, Assignment, Grading, and Course features that can display text, image, audio, and video material. Mobile learning system early detection of cancer is equipped with security features in the form of authentication and authorization.

This application consists of 9 features: (1) user management, (2) course management, (3) grading, (4) assignment, (5) enrollment, (6) group, (7) chat, (8) and (9) quiz. The application is used by 3 groups of user, namely: Administrator, Content Specialist (Instructor/Doctor Expert), and Participants. Administrators are tasked with (a) creating training, (b) creating classes, (c) participant registration. Content Specialists have responsibility to: (a) create topics, (b) upload learning content, (c) create quizzes, and (d) discuss with learners. Participants (students) follow the learning process online with the following activities: pre-test, implementation of learning, and post-test.

\subsection{Procedure}

This mobile learning early cancer detection application consists of the following procedure. First, the registration procedure. In order to participate in the course, candidates must register by filling out the registration form. In the registration form, there is an email address field to ensure that the email can be the identity of the potential participants. The emails sent automatically by the system contain links to the registration confirmation page. By clicking the link in the email, the candidate changes the status to be a participant.

Second, the course management procedure. An administrator plays a role in managing the course and course categories. Course categories are a place for courses. 
A course can only belong to one category. After the course is created, materials are prepared for learning activities.

Third, the procedure of preparation and delivery of learning materials. To prepare the materials, the specialist conducts the activities of collecting, compiling, and converting the material into digital format. Once the material is converted to digital form, the specialist handed it over to the administrator to upload to the backend system.

Fourth, quiz-making and assessment procedures. For quiz creation, the administrator uploads quiz questions. The quiz is in the form of multiple choice, so participants can only choose one of the answers. The answer of the participants is then assessed by the system automatically. If the correct answer exceeds $80 \%$, participants are considered to pass on the topic.

Fifth, the discussion procedure through the forum. Each user can create a new topic or give an opinion in the forum when they have logged in. Once a new topic is created, each user can express his opinion on the topic. The forum is one of the most helpful features to improve the understanding of learning materials through discussion among fellow learners and teachers. Forums should be well structured and have a rating feature for each post. Posts can be created in various formats and can have attachments (attachments). Attachment files are limited to 8MB. By joining the forum, participants can interact and be motivated to learn.

Sixth, monitoring procedures for the understanding of course participants. Quiz results and assignments from each user will be stored in the database. Then the value will be calculated and accumulated, whether it has reached the standard of graduation. When it has reached the passing grade, the user can print a graduation certificate.

\subsection{System Workflow}

The workflow of the mobile learning application is presented in Figure 2. The first step in this learning process is the creation of courses conducted by the administrator. In the course module, administrators have permissions to create new courses, change course data, and can delete them. While the specialist only has permission to view the module data of this course. The course, or also can be called a course, may consist of several learning topics.

The enrolled participants can then start the class by completing the pre-test. After completing the pretest, participants can download and study the learning materials even though they did not pass the pre-test. Participants can also discuss with other participants through the discussion forum feature. Then the participants must follow the topic comprehension quiz before they can download and study the subject matter further. Finally, after passing the quiz all the topics, participants must follow and pass the post-test to be passed and have the right to download the certificate of graduation.

The navigation diagram shows the relationship between home, login, courses, discussion, exam, and print certificate pages. The navigation diagram can be seen in Figure 3. 


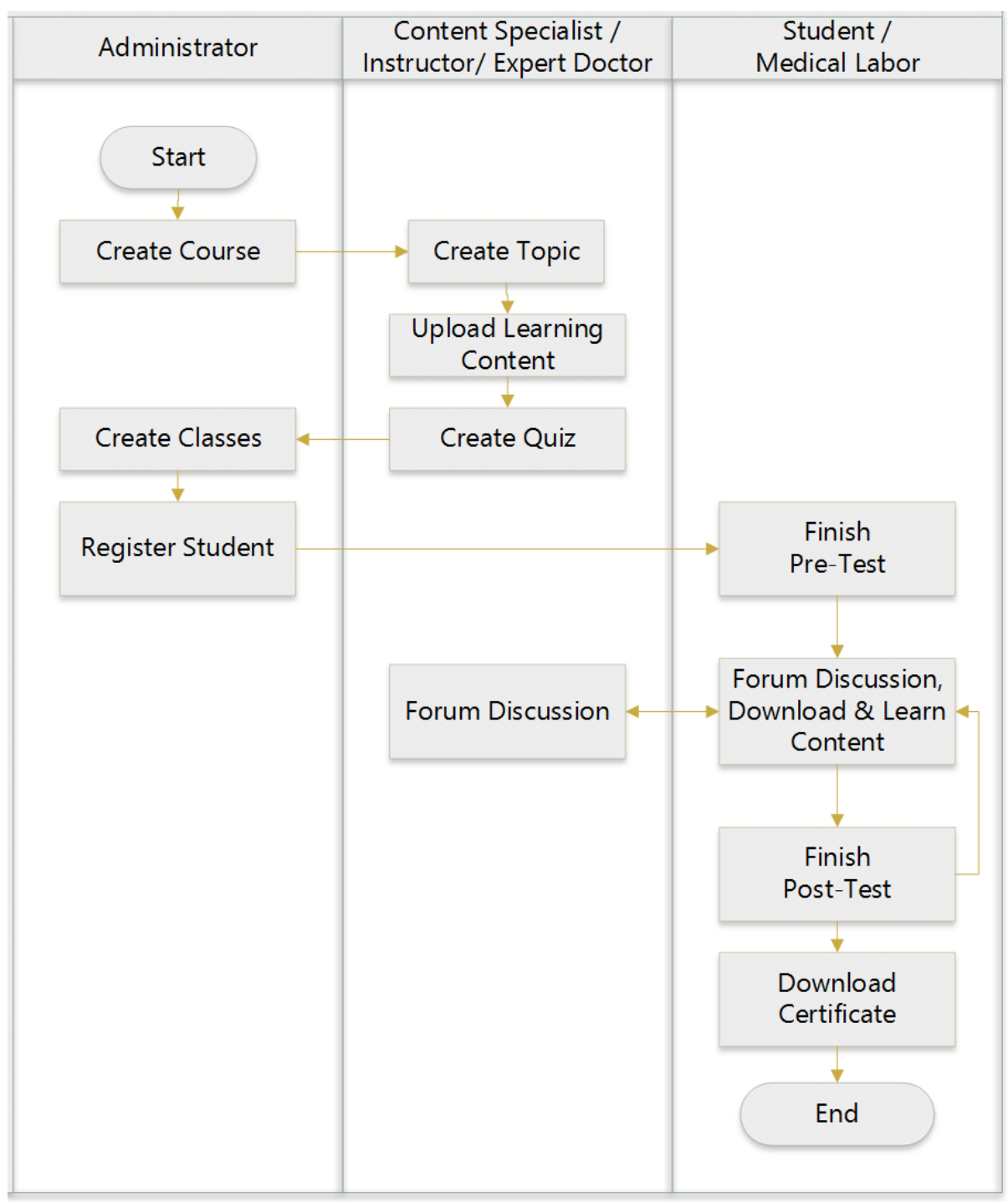

Fig. 2. Mobile Application Workflow 


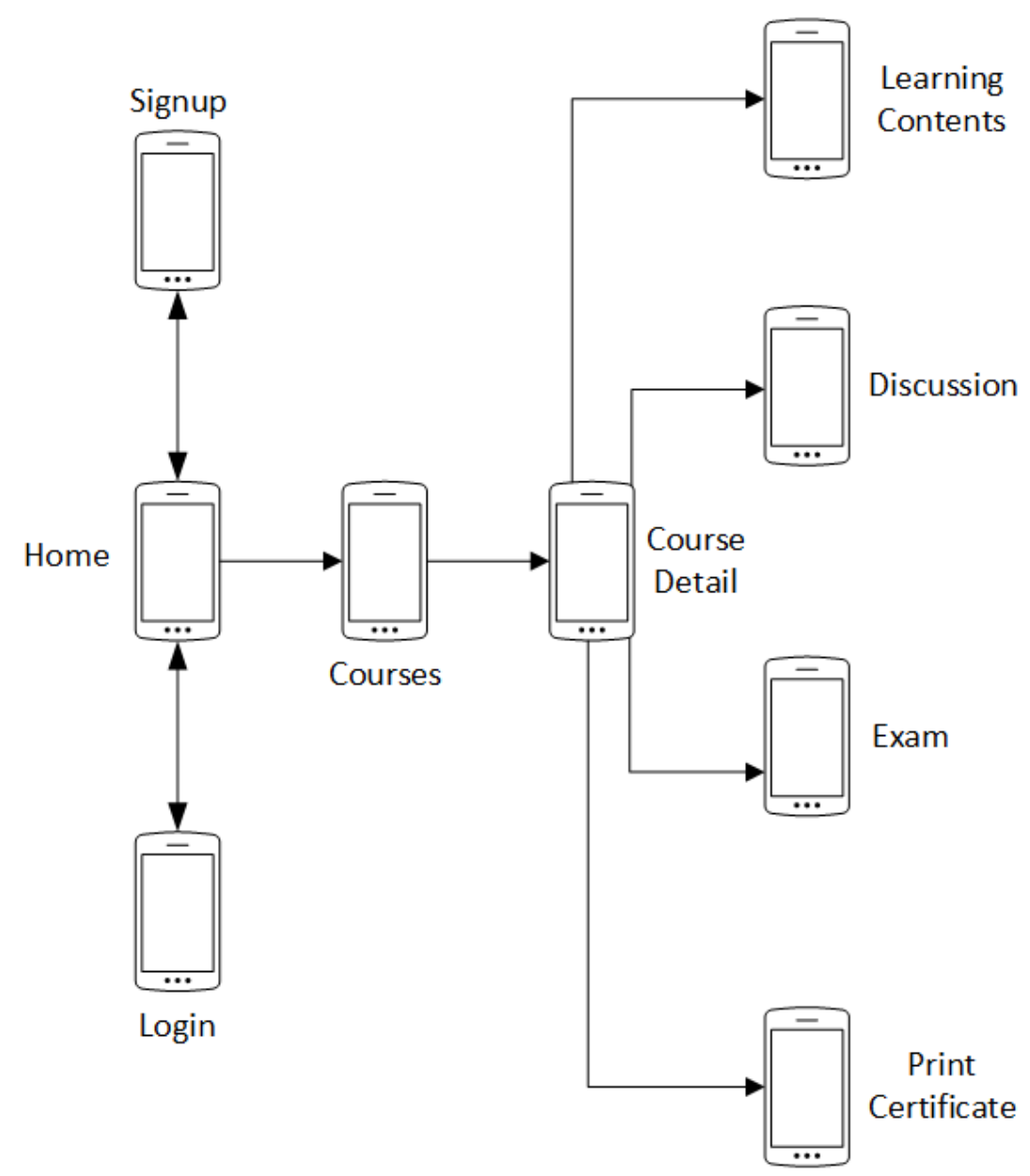

Fig. 3. Navigation Diagram

\subsection{User Interface Design}

The home page is the first one seen by the user. From the home page, the user can select other pages: choose the course, manage the user profile, access the content, take the exam, check whether any event in calendar, participate in forum, and downloading the certificate of graduation. Before starting learning and accessing all features, the user will be prompted to log in. The home page is shown in Figure 4.

In the header section, the user can select home, help, calendar, share, search, and login/logout menus. An application manual and a Q \& A feature for user assistance is provided on the help page. Schedule activities related to early cancer detection training can be seen on the calendar page. 


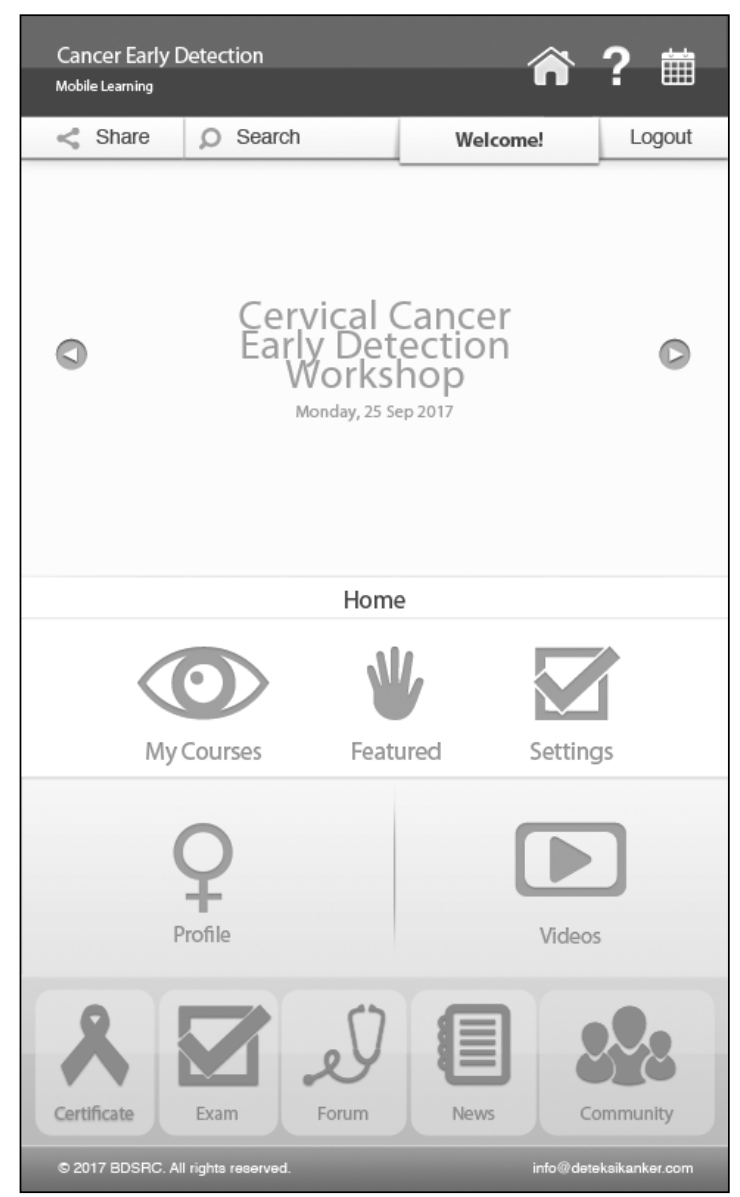

Fig. 4. Home page

In the footer section, there are 10 menus, consisting of my courses, featured, settings, profiles, videos, certificates, exam, forums, news, and community. User can view all the courses that are currently and have been taken to my courses page. On my courses page, the user can choose a course to be able to continue/review the learning process. The featured page displays a list of available courses along with a short description of the course. When the user has selected one of the courses, the course details will be displayed, consisting of the syllabus, the length of the learning course, and the terms and conditions of the course. User profile data management can be updated on the profile page. The learning process can also be fun for the user by watching the movie presented on the video page. Presentation of content with video streaming features such as video and audio can help learners to understand complex and procedural concepts that are difficult to explain through text and graphic media [28]. 
A list of exam result scores can be found on the exam page. On this page, the user can choose the test to retake in order to improve the grade. The exam feature is provided as a benchmark used in evaluating individual learners' abilities [29]. When have passed the final exam in a course, the user can download a passing certificate in pdf format on the certificate page for self-printing. The features of the discussion forums are presented with the aim of accommodating questions and feedback from learners to ask more about unfamiliar material. Each user can create a new topic or give an opinion in the forum when logged in. Once a new topic is created, each user can express his opinion on the topic. The forum is one of the most helpful features to improve the understanding of learning materials through discussion among fellow learners and teachers [30]. The news pages are used to display activities related to early cancer detection training, new courses to be opened, announcements, and other news related to cancer.

\section{Discussion}

The development of cervical cancer early detection mobile learning application starts from the needs to disseminate cancer early detection education contents that have been issued by the Ministry of Health. The dissemination program has not been widely implemented due to lack of knowledge and the high cost of information dissemination. This mobile learning development is a solution to the challenges above. It can educate new healthcare workers and medical personnel and improved their early detection of cervical cancer knowledge without geographical, time, physical barriers (for those with physical disabilities) and at minimum cost.

\section{Conclusion}

The development of mobile learning is based on helping government programs, especially the prevention of cancer, and establishing self-reliance and public awareness of the importance of early detection of cancer. This development is intended for medical personnel and health volunteer as well as an answer to the government's challenge in efforts to socialize cancer prevention knowledge to all Indonesians without being limited by geography, time and space. The results of the mobile learning design consist of nine features, the formation of three groups of users, and six procedures.

\section{Acknowledgment}

This study was funded by Applied Product Research Grant of the Directorate Research and Community Services, Ministry of Research, Technology, and Higher Education, Republic of Indonesia. 


\section{$7 \quad$ References}

[1] Huang, Y.-M., Hwang, W.-Y., \& Chang, K.-E. (2010). Guest Editorial - Innovations in Designing Mobile Learning Applications. Educational Technology \& Society, 13(3), 1-2.

[2] Spector, J. M. (2013). Foundations of educational technology: Integrative approaches and interdisciplinary perspectives. Routledge.

[3] Quinn, Clark N. (2011) Designing mLearning: Tapping into the mobile revolution for organizational performance. San Francisco: Pfeiffer. 256 pages. ISBN-13: 9780470604489.

[4] Alsaadat, K. (2009). Mobile Learning and University Teaching. International Conference on Education and New Learning Technologies (EDULEARN09), Barcelona, Spain.

[5] Vinu, P.V., Sherimon, P.C. and Krishnan, R. (2011) 'Towards pervasive mobile learning the vision of 21st century', Procedia Social and Behavioral Sciences, Vol. 15, pp.30673073. https://doi.org/10.1016/j.sbspro.2011.04.247

[6] Yuen, S. \& Wang, S. (2004). M-learning: Mobility in Learning. In J. Nall \& R. Robson (Eds.), Proceedings of E-Learn 2004--World Conference on E-Learning in Corporate, Government, Healthcare, and Higher Education (pp. 2248-2252). Washington, DC, USA: Association for the Advancement of Computing in Education (AACE).

[7] Ally, M. (2009). Mobile Learning: Transforming the Delivery of Education and Training. International Review of Research in Open and Distance Learning. Vol 10(4).

[8] Liu, T. Y., Tan, T. H., \& Chu, Y. L. (2009). Outdoor natural science learning with an RFIDsupported immersive ubiquitous learning environment. Educational Technology \& Society, 12(4), 161-175.

[9] Hsu, Y. -C., \& Ching, Y. -H. (2012). Mobile Microblogging: Using Twitter and Mobile Devices in an Online Course to Promote Learning in Authentic Contexts. The International Review of Research in Open and Distance Learning, 13(4), 211-227. https://doi.org/10.19173/irrodl.v13i4.1222

[10] Johnson, L., Adams, S., \& Cummins, M. (2012). Mobile apps. The NMC horizon report: 2012 higher education edition. Austin, Texas: The New Media Consortium.

[11] Hsu, Y. -C., Rice, K., \& Dawley, L. (2012). Empowering educators with Google's Android App Inventor: An online workshop in mobile app design. British Journal of Educational Technology, 43(1), E1-E5. https://doi.org/10.1111/j.1467-8535.2011.01241.x

[12] Muljo, H., H., Perbangsa, A.S., \& Pardamean, B., (2015). Online Learning Content and Learning Management System for Early Detection of Cervical Cancer. International Journal of Digital Content Technology and its Applications. Vol 9(1), 54-63.

[13] Velev, Dimiter G., (2014). Challanges and Opportunities of Cloud-Based Mobile Learning. Internasional Journal of Information and Education Technology. 4(1), 49-53. https://doi.org/10.7763/IJIET.2014.V4.367

[14] Al Hassan, E.I.K., (2015). Mobile Learning New Technique to Contribute the Development of Distance Learning Courses, as views from Specialist of Information and Instructional Technology in Sundanese Universities. Journal of Education and Human Development. 4(1), 269-276. https://doi.org/10.15640/jehd.v4n1a24

[15] Botzer, G. \& Yerushalmy, M., (2007), Mobile application for mobile learning. IADIS International Conference on Cognition and Exploratory Learning in Digital Age (CELDA 2007):313-316

[16] Marty, Paul F.; Mendenhall, Anne; Douglas, Ian; Southerland, Sherry A.; Sampson, Victor; Kazmer, Michelle M.; Alemanne, Nicole; Clark, Amanda; Schellinger, Jennifer. (2013). The Iterative Design of a Mobile Learning Application to Support Scientific Inquiry. Journal of Learning Design. 6(2), 41-66. https://doi.org/10.5204/jld.v6i2.124 
[17] Al-Fahad, F.N., (2009). Students' Attitudes and Perceptions Towards the Effectiveness Of Mobile Learning In King Saud University, Saudi Arabia. The Turkish Online Journal of Educational Technology. 8(2), 111-119.

[18] Morris, N.P.; Lambe, J.; Cicconet. J.; \& Swinnerton, B., (2016). Mobile Technology: Students Percieved Benefits of Apps for Learning Neuroanatomy. Journal of Computer Assisted Learning. 32, 430-442. https://doi.org/10.1111/jcal.12144

[19] Hariry, N., A., E. (2015). Mobile Phones as Useful Language Learning Tools. European Scientific Journal., 11(16), 289-317.

[20] Nielsen, J., and Budiu, R., (2013). Mobile Usability. Berkeley: New Riders.

[21] Kukulska-Hulme, A., \& Traxler, J. (2005). Mobile Learning: A Handbook for Educators and Trainers. London: Routledge.

[22] Elias, T. (2011). Universal Instructional Design Principles for Mobile Learning, International Review of Research in Open and Distributed Learning. Vol. 12(2), pp1-10. https://doi.org/10.19173/irrodl.v12i2.965

[23] Aldoobie, N. (2015). ADDIE Model Analysis phase. American International Journal of Contemporary Research, 5(6), 68-72. http://www.aijcrnet.com/journals/Vol_5_No_6_ December_2015/10.pdf.

[24] Szekely, A., Talanow, R., \& Bagyi, P. (2013). Smartphones, tablets and mobile applications for radiology. European Journal of Radiology, 829-836. https://doi.org/10.1016/j.ejrad.2012.11.034

[25] Hengming, F., Jia, C., \& Bin, X. (2013). The Interaction Mechanism based on JSON for Android Database Application. Information Technology Journal, 224-228. https://doi.org/10.3923/itj.2013.224.228

[26] Bhosale, S. T., Patil, T., \& Patil, P. (2015). SQLite: LIght Database System. International Journal of Computer Science and Mobile Computing, 882-885.

[27] Rathi, K. V, Kosale, S. S., Kumar, M., \& Thote, S. R. (2012). Implementation of a Mobile Campus Using Open Source Software, 1(1), 9-12.

[28] Klass, B. (2003). Streaming Media in Higher Education: Possibilities and Pitfalls. Syllabus, 16(11).

[29] Kim, K.J., Han, J.H., Park, I.B., \& Kee, C.W. (2009). Medical Education in Korea: The eLearning Consortium. Medical Teacher. (31): e397 - e401 https://doi.org/10.1080/ 01421590902744902

[30] Pandey, S. R., \& Pandey, S. (2009). Developing a More Effective and Flexible Learning Management System (LMS) for the Academic Institutions using Moodle. International Conference on Academic Libraries, 249-254.

\section{Authors}

Hery Harjono Muljo is a researcher at Bioinformatics \& Data Science Research Center and a lecturer at Accounting Program, Bina Nusantara University, Jakarta, Indonesia. His research expertise is in developing management information system of health institutions such as hospitals and clinics.

Anzaludin Samsinga Perbangsa is a researcher at Bioinformatics \& Data Science Research Center and a lecturer at School of Information Systems, Bina Nusantara University, Jakarta, Indonesia. His research expertise is in developing tools to investigate the interplay of genetic and environmental factors in agriculture and has developed agricultural germplasm database. 
Yulius is a researcher at Bioinformatics \& Data Science Research Center and a lecturer at School of Information Systems, Jakarta, Indonesia. His current research interest focus on developing tools and strategies with IT solution to face global IT trends.

Bens Pardamean is Director of Bioinformatics \& Data Science Research Center and Associate Professor of Computer Science, Bina Nusantara University, Jakarta, Indonesia. His research expertise is in information technology, bioinformatics, and education, including a strong background in database systems, computer networks, and quantitative research.

Article submitted 10 October 2017. Final acceptance 21 January 2018. Final version published as submitted by the authors. 